\title{
Sensory Problems in Children with Epilepsy
}

\author{
Pooja Singh ${ }^{1}$, Chavan Shashidhar Rao ${ }^{2}$ \\ ${ }^{1}$ Occupational Therapist, Manipal College of Allied Health Sciences, Manipal University, Manipal \\ ${ }^{2}$ Associate Professor, Manipal University, Manipal \\ Place of Research - Manipal College of Allied Health Sciences, Manipal University, Manipal
}

\begin{abstract}
Objective: The purpose of this research is to study the sensory responsivity pattern of children with epilepsy and compare it in children with the typical development and global developmental delay. Method: Parents of 30 children with epilepsy, 30 children with global developmental delay (GDD) and 60 typical children 7 to 36 months of age completed the infant toddler sensory profile questionnaire. Parents used a 5-point likert scale to report the percentage of time their children engaged in each behavior. Chi -square test was used to analyze the difference in the performance of typical children, children with GDD and children with epilepsy in the five sensory processing sections and in the four quadrants. Results: The performance of children with epilepsy was significantly different $(p<0.01)$ from typical children on all sensory processing sections and quadrants. Significant difference was observed in the auditory, tactile and oral sensory processing sections between typical children and children with GDD. Significant difference was observed in the visual, tactile, vestibular and oral sensory processing sections when compared with the performance of children with epilepsy and children with GDD. Conclusion: Children with epilepsy have deficits in sensory processing abilities as measured by the sensory profile that affect their daily performance.
\end{abstract}

Keywords: Epilepsy, global developmental delay, sensory profile, sensory processing, Infant toddler sensory profile

\section{Introduction}

Epilepsy has a multitude effect on the child development. Epilepsy occurs in approximately $0.5 \%$ to $1 \%$ of the population. The incidence is highest in children younger than three year of age. Severity of epilepsy plays a major role in affecting quality of life of these children apart from primary illness (Singhi, 2010).

Epilepsy has neurological origin and alters the neurophysiologic mechanism, which consequently affects the motor and sensory processing of the environmental inputs. Motor involvements include tonic clonic posturing of limb and sensory involvement can range from altered sensorium to having sensory registration and discriminatory dysfunction.

Based on sensory integrative theory (Ayres, 1972), the sensory process of input received by sensory system such as tactile, visual, and kinesthesia provides base for emergence of body scheme, which in turn contributes for the perceptual and behavioral development. Jean Ayres (1979) emphasizes that the higher abilities such as organization and regulation of behavior is direct consequences of sensory integration ability of nervous system. There is interplay between poor sensory processing and behavioral dysfunction (Bundy, 2002).

Epilepsy because of its neurological origin may arise due to defect in single or multiple location involving cortical and sub cortical areas in brain. It is assumed that sensory integration function primarily to occur at sub-cortical or brain stem level. The areas attributed for sensory integration processing are brain stem, thalamus, vestibular nuclei and their inter connections, reticular formation, cerebellum, limbic system, temporal and parietal lobe. The role of cortex is related to praxis abilities, which are direct consequences of normal sensory integration occurring at lower system (Bundy, Lane \& Murray, 2002).Consequently, we assume that epileptogenic focus involving in any of these areas can interfere with sensory processing and integration abilities in these children.

\subsection{Need for the Study}

Various authors (Rutter et al., 1979; Austin et al., 1992) have studied behavioral problem in children with epilepsy. However defect in sensory registration and modulation has not well documented in children with epilepsy. Therefore, the purpose of this research is to study the sensory responsivity pattern of children with epilepsy and compare it in children with the typical development and global developmental delay.

\section{Review of Literature}

The areas reviewed are as follows:

1) Behavioral problems in epilepsy

2) Evidence supporting Dunn model of sensory processing

\subsection{Epilepsy and associated behavioral problems}

Epilepsy has neurological origin and is assumed to reflect behavior and cognitive impairments in children. Seizure onset before one year of age is common, and is reported in over $60 \%$ of cases. Developmental delay is one of the common manifestations for children with epilepsy. Developmental delay may arise due to epilepsy or may be an associated finding with epilepsy. Children with early onset and high seizure frequency are at a higher risk of developing behavioral disorders. It has been postulated that children with epilepsy have more behavioral problems when compared to children without epilepsy having similar IQ (Oostrom et al., 2003). Social and behavioral impairment like temper tantrums, stubbornness, easy distractibility, are common and can be present in spite of normal intelligence (Buelow et al., 2003).

Children with epilepsy have reported to have co-morbidities like attention deficit hyperactive disorder, autism, 


\section{International Journal of Science and Research (IJSR) \\ ISSN (Online): 2319-7064 \\ Index Copernicus Value (2013): 6.14 | Impact Factor (2014): 5.611}

developmental delay etc. ADHD has reported in 8-77 \% of children with epilepsy. Children with severe epilepsy are at high risk for ADHD, and ADHD is a significant predictor of poor health related quality of life in epilepsy (Singhi, 2010).

Children with autistic spectrum disorder have an increased prevalence of seizures. One-third cases of autism are known to have epilepsy. Epilepsy may itself result in autistic symptoms or may aggravate preexisting autistic symptoms (Clarke et al., 2006).

Accumulating body of literature describes sensory processing as an important factor in human behavior. Dunn (2001), describe four patterns of sensory processing that occurs across all age groups, and seem to occur more abnormal in vulnerable populations. Sensory processing knowledge is useful for planning interventions that support children to have successful and satisfying experiences in everyday life.

Based on data from more than 1000 children with and without disabilities, Dunn hypothesized that there is a relationship between a person's nervous system operations and self-regulation strategies, and the interaction of these functions creates four basic patterns of sensory processing i.e. low registration, sensation seeking, sensation avoiding and sensory sensitivity (Dunn and Brown, 1997).

\subsection{Evidence supporting Dunn's model of sensory processing}

Over the last decade, researchers have tested the validity and reliability of Dunn's Models of sensory processing of children and adults with and without disabilities across the life span using three age-appropriate questionnaires (The Infant/Toddler Sensory Profile, Sensory Profile, and Adolescent/Adult Sensory Profile).

National sample of 589 toddlers/infants (Dunn \& Daniels, 2001; Dunn, 2002), 1115 children and 950 adolescent/adults (Dunn \& Westman, 1997; Dunn, 1999) were tested. Results suggested that most of the people have moderate response to sensory events in everyday life and only small percentage of people without disabilities have intense sensory response just like cohorts with disabilities. Vulnerable children have more chances of having extreme pattern of sensory processing which interferes with everyday life.

Evidence accumulated so far suggest that vulnerable children (child with autism, ADHD Asperger's syndrome, Fragile $\mathrm{X}$ syndrome) are much more likely to have intense sensory response pattern (Baranek, 1999; Kientz \& Dunn, 1996; Ermer \& Dunn, 1997; Dunn \& Bennett, 2002; Myles et al., 2004). As described earlier, epilepsy is more common in all these vulnerable conditions and hence intense sensory response patterns are expected in children with epilepsy.

Dunn and her colleagues developed the sensory profile tool to determine sensory integration dysfunction in children. It is a standardized tool for measuring sensory abilities of children and effect of those abilities on their functional performance. It is a judgment-based questionnaire evaluating how a child responds to visual, auditory, touch, tactile, movement and multisensory stimuli. It generally consists of statement or questions directed to parent or caregiver about a child behavior while the child is engaged in functional activities.

In a pilot study evaluating the performance of children without disability on the sensory profile, Dunn (1994) found that majority of the items (67 out of 99 items) were uncommon behaviors for children without disabilities, suggesting that these items may be useful for identifying difficulties among children with various disabilities.

Ermer and Dunn (1997) in their study used sensory profile tool to study the performance of children with and without disability. They divided the study population into three groups (children with autism, children with ADHD, and children without disabilities). They identified 46 items and 4 factors of discrimination on the sensory profile among children with autism spectrum disorders, children with attention deficit hyperactive disorder and children without disabilities. The authors concluded that the sensory profile was an effective tool for discriminating children with and without disability.

Watling et al. (2000) studied the sensory-based behaviors of young children with autism and without autism on the sensory profile. Parents of children with and without autism completed sensory profile questionnaire. Result showed that performance of the children with autism was different from that of children without autism on eight of 10 factors. They suggested that sensory profile is able to measure sensory processing deficits in young children with autism.

Prakash \& Vaishampayan (2007) in their study compared the sensory processing abilities of children with cerebral palsy and typical children on sensory the sensory profile. Results showed that 40 out of 125 items and 7 of 14 components were different between the children with cerebral palsy and typical children. They suggested that sensory profile is useful to discriminate between children with cerebral palsy and typical children and can identify the presence of sensory processing problems in children with cerebral palsy.

The clinical condition seen by occupational therapist constitutes children with epilepsy as a major potion. Furthermore, they seem to present with lot of sensory issues akin to other childhood disorders in whom sensory problems are represented. However, sensory responsivity patterns of children with epilepsy are not explored. In fact, they constitute the exclusion criteria for many studies (Kientz \& Dunn, 1996; Ermer \& Dunn, 1997; Renee et al., 2000; Prakash \& Vaishampayan, (2007).

Therefore, the study is planned to explore the sensory responsivity pattern of children with epilepsy disorder.

\subsection{Research question}

1) Does significant difference exist between the scores of children with epilepsy, typical children and children with global developmental delay on infant toddler sensory profile? 


\section{International Journal of Science and Research (IJSR) \\ ISSN (Online): 2319-7064 \\ Index Copernicus Value (2013): 6.14 | Impact Factor (2014): 5.611}

2) How is the responsivity pattern between groups on the sensory profile items?

\subsection{Aim of the study}

To determine whether the sensory profile can discriminates children with epilepsy from children who are typically developing.

\subsection{Hypothesis}

$\mathrm{H}_{1}$ : Children with epilepsy differ from the typical children and children with global developmental delay on infant toddler sensory profile.

\section{Methodology}

\subsection{Study design}

Cross sectional descriptive study design with convenient sampling method.

\subsection{Participants}

Total 120 participants between the age group 7 to 36 months were included in the study. The experimental group comprised of thirty children with an established diagnosis of epilepsy, referred to occupational therapy department. The other two groups comprised of thirty children with developmental delay and sixty typical children aged 7 months to 36 months. Children were considered "typical" when not taking medication and not receiving any special services. Typical children were recruited from a day care centre or crèche.

\subsection{Inclusion criteria}

1) Children with epilepsy.

2) Children with developmental delay.

3) Age group $\leq 3$ year.

4) Children with no medical illness in recent past, which might have affected their mood or behavior.

\subsection{Exclusion criteria}

1) Medical conditions like autism, ADHD, children with restricted, repetitive and stereotyped behaviors, cerebral palsy.

2) Deaf and blind child.

\subsection{Variables}

Dependent: Score obtained on the infant toddler sensory profile questionnaire

Independent: Age

\subsection{Instrumentation}

The integrity of sensory integration mechanism is assessed by studying the adaptive responses to challenges (Ayres, 1972) or by obtaining the sensory responsivity patterns to a variety of commonly occurring sensory experience in everyday life (Dunn, 2004). Sensory profile is one of the commonest tools, used to identify sensory modulation disorder in children because of poor sensory integration mechanism. The Infant Toddler Sensory Profile (Dunn, 2002) measures sensory processing skills among infants and toddlers. It highlights the sensory processing strengths and barriers in relation to daily childhood occupations. The caregiver questionnaire contains two versions of the questions, one version for children aged birth to six month and another version for children aged seven to thirty six months. The birth to six months questionnaire consists thirty-six items related to general, auditory, visual, tactile, and vestibular processing. The seven to thirty six months questionnaire consists forty- eight items in the above five categories plus oral sensory processing. The parents or caregiver rates each item on a 5-point likert scale for the frequency of the behavior that occurs in the home or community environment. The frequencies of the behaviors are scored as: always, frequently, occasionally, seldom, and never. Behavior that occurs as $100 \%$ of the time are described as always and scored as 1 , whereas behaviors seen as never or $0 \%$ of the time are scored as 5 .

For each sensory processing sections (i.e., general processing, auditory processing, visual processing, vestibular processing, tactile processing, and oral sensory processing) raw scores are calculated. These scores are further grouped into four quadrant scores: Low Registration, Sensation Seeking, Sensory Sensitivity, and sensation avoiding. A low threshold score is calculated by summing sensitivity and avoiding quadrant scores. Lower score indicate a higher frequency of response.

Infant/Toddler Sensory Profile is sensitive enough to differentiate sensory processing difficulties in children with disability from their typically developing peers. Internal reliability for the Infant/Toddler Sensory Profile ranged from 0.42 to 0.86 . In addition, test-retest reliability analyses yielded a correlation coefficient of .86 for section scores and .74 for quadrant scores, indicating that the Infant/Toddler SP has an acceptable degree of stability over time (Dunn 2002).

\subsection{Procedure}

All the parents participated in the study voluntarily. Thirty children diagnosed with epilepsy and global developmental delay, thirty children with global developmental delay and sixty typical children between the age group of seven-thirty six months were included for the study. Demographic details of the child like the name, age sex, developmental history, EEG findings and information about the seizure variables like the type of epilepsy, duration of illness, frequency of epilepsy and medications taken were collected.

After explaining the study to the parents, consent forms and infant toddler sensory profile caregiver questionnaire were given (The material are shown in the photograph no.1and an example is given in appendix-B). Parents were allowed to complete the forms at their convenience. The prime investigator clarified the queries faced by the parents in filling up the questionnaire. The completed profiles were collected from the parents and scoring was done according to the frequency of response of the child. 


\section{International Journal of Science and Research (IJSR) \\ ISSN (Online): 2319-7064 \\ Index Copernicus Value (2013): 6.14 | Impact Factor (2014): 5.611}

\subsection{Operational definitions}

- Sensory processing: Refers to the way the nervous system receive messages from the senses and turns them into appropriate motor and behavioral responses.

- Sensory processing dysfunction: It is a condition that exists when sensory signal do not get organized into appropriate responses.

- Epilepsy: Two or more unprovoked seizure occurring 24 hours apart resulting in a temporary disturbance of motor, sensory, or mental function

- Developmental delay: Any significant lag in a child's physical, cognitive, behavioral, emotional, or social development, in comparison with norms

\subsection{Scoring}

Scoring was done as per the manual instructions of infant toddler sensory profile. The parents responded the questionnaire in one of the following categories such as always, frequently, occasionally, seldom and never. These were awarded scores based on a five point likert scale. The score of one indicated that the behavior occurs always or $100 \%$ of the time and score of five indicated never or $0 \%$ of time.

\begin{tabular}{|c|l|}
\hline Score & Frequency of behavior \\
\hline 1 & $\begin{array}{l}\text { Always: when presented with the opportunity the child } \\
\text { responds in the manner described every time or } 100 \% \text { of } \\
\text { the time }\end{array}$ \\
\hline 2 & Frequently or $75 \%$ of the time \\
\hline 3 & Occasionally or $50 \%$ of the time \\
\hline 4 & Seldom or $25 \%$ of the time \\
\hline 5 & $\begin{array}{l}\text { Never: when presented with the opportunity, the child } \\
\text { never responds in the manner of } 0 \% \text { of the time }\end{array}$ \\
\hline
\end{tabular}

Raw score of sensory processing section was determined by adding the item scores for each section. Raw scores of quadrant grid was calculated by transferring the item raw scores from the caregiver questionnaire to the corresponding item number on the quadrant grid. Adding the raw score column for each quadrant, quadrant raw score total was calculated. The child's score for each quadrant and sensory processing section was transferred to the corresponding quadrant raw score total and section raw score total. Quadrant and section raw score total was plotted in the appropriate classification column, (Typical performance, Probable difference, or Definite difference) according to the appropriate age band for each quadrant and section.

\subsection{Data analysis}

Descriptive analysis of the total data set was completed for the children with global developmental delay $(n=30)$, children with epilepsy and global developmental delay $(n=30)$ and typical children $(n=60)$ to identify the distribution of response on each item on the Infant Toddler Sensory Profile. The Chi -square tests were computed to observe the difference in the performance of typical children, children with global developmental delay and children epilepsy in the five sensory processing sections (auditory, visual, tactile, vestibular and oral sensory). Differences in the scores obtained on the four quadrants (Low registration, sensation seeking, sensory sensitivity and sensation avoiding) were also analyzed by chi-square test. SPSS version 16.0 was used to conduct the analysis.

\section{Results}

\subsection{Sample characteristics}

Total 120 children (60 typical, 30 global developmental delay and 30 children with epilepsy and global developmental delay) met the inclusion criteria and were enrolled in the study. The summary of demographic characteristics of participants is listed in table 1.

Table 1: Descriptive characteristics of children with - epilepsy - global developmental delay (GDD) and - typical children

\begin{tabular}{|l|c|c|c|l|}
\hline \multirow{2}{*}{ Gender } & \multicolumn{4}{|c|}{ Groups } \\
\cline { 2 - 5 } & $\begin{array}{c}\text { Typical children } \\
(N=60)\end{array}$ & $\begin{array}{c}\text { GDD } \\
(N=30)\end{array}$ & $\begin{array}{l}\text { Epilepsy } \\
(N=30)\end{array}$ & $\begin{array}{l}\text { Total } \\
(N=120)\end{array}$ \\
\hline Female (\%) & $24(40 \%)$ & $13(43.33 \%)$ & $20(66.66 \%)$ & $57(47.5 \%)$ \\
Male (\%) & $36(60 \%)$ & $17(56.66 \%)$ & $10(33.33 \%)$ & $63(52.5 \%)$ \\
\hline Mean age (SD) & $19.43(8.64)$ & $20.77(8.89)$ & $20.6(7.39)$ & \\
\hline
\end{tabular}

GDD: global developmental delay

Performance of the typical children, children with global developmental delay (GDD) \& children with epilepsy in sensory processing sections (general processing, auditory processing, visual processing, tactile processing vestibular processing and oral sensory processing) is listed in Table 2. 


\section{International Journal of Science and Research (IJSR) \\ ISSN (Online): 2319-7064 \\ Index Copernicus Value (2013): 6.14 | Impact Factor (2014): 5.611}

Table 2: Performance of typical children, children with global developmental delay (GDD) and children with epilepsy and global developmental delay in sensory processing sections

\begin{tabular}{|c|c|c|c|c|c|c|c|c|c|c|c|c|c|c|c|}
\hline & \multicolumn{5}{|c|}{ Typical $(\mathrm{N}=60)$} & \multicolumn{5}{|c|}{ GDD $(\mathrm{N}=30)$} & \multicolumn{5}{|c|}{ Epilepsy $(\mathrm{N}=30)$} \\
\hline & \multirow[t]{2}{*}{ T.P } & \multicolumn{2}{|c|}{ P.D } & \multicolumn{2}{|c|}{ D.D } & \multirow[t]{2}{*}{ T.P } & \multicolumn{2}{|l|}{ P.D } & \multicolumn{2}{|l|}{ D.D } & \multirow{2}{*}{ T.P } & \multirow{2}{*}{ P.D } & \multirow[b]{2}{*}{$\mathrm{L}$} & \multicolumn{2}{|l|}{ D.D } \\
\hline & & $\mathrm{M}$ & $\mathrm{L}$ & $\mathrm{M}$ & $\mathrm{L}$ & & $\mathrm{M}$ & $\mathrm{L}$ & $\mathrm{M}$ & $\mathrm{L}$ & & & & $\mathrm{M}$ & $\mathrm{L}$ \\
\hline $\begin{array}{l}\text { Auditory } \\
(\%)\end{array}$ & $\begin{array}{l}59 \\
(98)\end{array}$ & $\begin{array}{l}0 \\
(0)\end{array}$ & $\begin{array}{l}1 \\
(2)\end{array}$ & $\begin{array}{l}0 \\
(0)\end{array}$ & $\begin{array}{l}0 \\
(0)\end{array}$ & $\begin{array}{l}23 \\
(76)\end{array}$ & $\begin{array}{l}2 \\
(7)\end{array}$ & $\begin{array}{l}1 \\
(3)\end{array}$ & $\begin{array}{l}4 \\
\text { (13) }\end{array}$ & $\begin{array}{l}0 \\
(0)\end{array}$ & $\begin{array}{l}18 \\
(60)\end{array}$ & $\begin{array}{l}2 \\
(7)\end{array}$ & $\begin{array}{l}2 \\
(7)\end{array}$ & $\begin{array}{l}8 \\
(27)\end{array}$ & $\begin{array}{l}0 \\
(0)\end{array}$ \\
\hline $\begin{array}{l}\text { Visual } \\
(\%)\end{array}$ & $\begin{array}{l}58 \\
(96)\end{array}$ & $\begin{array}{l}1 \\
(2)\end{array}$ & $\begin{array}{l}1 \\
(2)\end{array}$ & $\begin{array}{l}0 \\
(0)\end{array}$ & $\begin{array}{l}0 \\
(0)\end{array}$ & $\begin{array}{l}26 \\
(87) \\
\end{array}$ & $\begin{array}{l}3 \\
(10)\end{array}$ & $\begin{array}{l}1 \\
(3)\end{array}$ & $\begin{array}{l}0 \\
(0)\end{array}$ & $\begin{array}{l}0 \\
(0)\end{array}$ & $\begin{array}{l}17 \\
(57) \\
\end{array}$ & $\begin{array}{l}4 \\
(13) \\
\end{array}$ & $\begin{array}{l}2 \\
(7)\end{array}$ & $\begin{array}{l}6 \\
(20) \\
\end{array}$ & $\begin{array}{l}1 \\
(3)\end{array}$ \\
\hline $\begin{array}{l}\text { Tactile } \\
(\%)\end{array}$ & $\begin{array}{l}58 \\
(96)\end{array}$ & $\begin{array}{l}0 \\
(0)\end{array}$ & $\begin{array}{l}1 \\
\text { (2) }\end{array}$ & $\begin{array}{l}1 \\
(2)\end{array}$ & $\begin{array}{l}0 \\
(0)\end{array}$ & $\begin{array}{l}25 \\
(83)\end{array}$ & $\begin{array}{l}2 \\
(7)\end{array}$ & $\begin{array}{l}3 \\
(10)\end{array}$ & $\begin{array}{l}0 \\
(0)\end{array}$ & $\begin{array}{l}0 \\
(0)\end{array}$ & $\begin{array}{l}20 \\
(67)\end{array}$ & $\begin{array}{l}6 \\
(20)\end{array}$ & $\begin{array}{l}1 \\
(7)\end{array}$ & $\begin{array}{l}3 \\
(10)\end{array}$ & $\begin{array}{l}0 \\
(0)\end{array}$ \\
\hline $\begin{array}{l}\text { Vestibular } \\
(\%)\end{array}$ & $\begin{array}{l}60 \\
(100) \\
\end{array}$ & $\begin{array}{l}0 \\
(0)\end{array}$ & $\begin{array}{l}0 \\
(0)\end{array}$ & $\begin{array}{l}0 \\
(0) \\
\end{array}$ & $\begin{array}{l}0 \\
(0)\end{array}$ & $\begin{array}{l}29 \\
(97) \\
\end{array}$ & $\begin{array}{l}0 \\
(0) \\
\end{array}$ & $\begin{array}{l}0 \\
(0) \\
\end{array}$ & $\begin{array}{l}0 \\
(0)\end{array}$ & $\begin{array}{l}1 \\
(3) \\
\end{array}$ & $\begin{array}{l}11 \\
(37) \\
\end{array}$ & $\begin{array}{l}7 \\
(23) \\
\end{array}$ & $\begin{array}{l}3 \\
(10) \\
\end{array}$ & $\begin{array}{l}9 \\
(30) \\
\end{array}$ & $\begin{array}{l}0 \\
(0) \\
\end{array}$ \\
\hline $\begin{array}{l}\text { Oral sensory } \\
(\%)\end{array}$ & $\begin{array}{l}60 \\
(100) \\
\end{array}$ & $\begin{array}{l}0 \\
(0)\end{array}$ & $\begin{array}{l}0 \\
(0)\end{array}$ & $\begin{array}{l}0 \\
(0)\end{array}$ & $\begin{array}{l}0 \\
(0)\end{array}$ & $\begin{array}{l}26 \\
(87)\end{array}$ & $\begin{array}{l}2 \\
(7)\end{array}$ & $\begin{array}{l}1 \\
(3)\end{array}$ & $\begin{array}{l}0 \\
(0)\end{array}$ & $\begin{array}{l}1 \\
\text { (3) }\end{array}$ & $\begin{array}{l}18 \\
(60) \\
\end{array}$ & $\begin{array}{l}8 \\
(27) \\
\end{array}$ & $\begin{array}{l}2 \\
\text { (3) }\end{array}$ & $\begin{array}{l}1 \\
\text { (3) }\end{array}$ & $\begin{array}{l}1 \\
\text { (3) }\end{array}$ \\
\hline
\end{tabular}

GDD- global developmental delay; T.P-typical performance; P.D-probable difference; D.D- definite difference; M- more than others; L-less than others

Performance of the typical children, children with global developmental delay (GDD) \& children with epilepsy on all four quadrants (low registration, sensory seeking, sensory sensitivity and sensation avoiding) is listed in Table 3 .

Table 3: Performance of typical children, children with global developmental delay (GDD) and children with epilepsy and global developmental delay in quadrants

\begin{tabular}{|c|c|c|c|c|c|c|c|c|c|c|c|c|c|c|c|}
\hline & \multicolumn{5}{|c|}{ Typical $(\mathrm{N}=60)$} & \multicolumn{5}{|c|}{ GDD $(\mathrm{N}=30)$} & \multicolumn{5}{|c|}{ Epilepsy $(\mathrm{N}=30)$} \\
\hline & \multirow[t]{2}{*}{ T.P } & \multicolumn{2}{|c|}{ P.D } & \multicolumn{2}{|c|}{ D.D } & \multirow[t]{2}{*}{ T.P } & \multicolumn{2}{|c|}{ P.D } & \multicolumn{2}{|c|}{ D.D } & \multirow[t]{2}{*}{ T.P } & \multirow{2}{*}{\begin{tabular}{|l|} 
P.D \\
$M$
\end{tabular}} & \multirow[b]{2}{*}{$\mathrm{L}$} & \multirow{2}{*}{\begin{tabular}{|l|} 
D.D \\
M
\end{tabular}} & \multirow[b]{2}{*}{$\mathrm{L}$} \\
\hline & & $M$ & $\mathrm{~L}$ & $\mathrm{M}$ & $\mathrm{L}$ & & $\mathrm{M}$ & $\mathrm{L}$ & $M$ & $\mathrm{~L}$ & & & & & \\
\hline Quadrant 1 & 60 & 0 & 0 & 0 & 0 & 18 & 1 & 1 & 10 & 0 & 11 & 4 & 0 & 15 & 0 \\
\hline$(\%)$ & -100 & 0 & 0 & 0 & 0 & -61 & -3 & -3 & -33 & 0 & -37 & -13 & 0 & -50 & 0 \\
\hline Quadrant 2 & 57 & 1 & 1 & 0 & 1 & 24 & 0 & 4 & 0 & 2 & 15 & 3 & 4 & 0 & 8 \\
\hline$(\%)$ & -94 & -2 & -2 & 0 & -2 & -80 & 0 & -13 & 0 & -7 & -50 & -10 & -13 & 0 & -27 \\
\hline Quadrant 3 & 55 & 3 & 1 & 1 & 0 & 27 & 1 & 2 & 0 & 0 & 17 & 7 & 0 & 6 & 0 \\
\hline$(\%)$ & -92 & -4 & -2 & -2 & 0 & -90 & -3 & -7 & 0 & 0 & -57 & -23 & 0 & -20 & 0 \\
\hline Quadrant 4 & 58 & 2 & 0 & 0 & 0 & 30 & 0 & 0 & 0 & 0 & 15 & 9 & 2 & 4 & 0 \\
\hline$(\%)$ & -97 & -3 & 0 & 0 & 0 & -100 & 0 & 0 & 0 & 0 & -50 & -30 & -7 & -13 & 0 \\
\hline
\end{tabular}

GDD- global developmental delay; T.P-typical performance; P.D-probable difference; D.D- definite difference; M- more than others; L-less than others: Quadrant 1- Low registration, Quadrant 2- sensation seeking, Quadrant 3-sensation sensitivity, Quadrant 4- Sensation Avoiding.

To determine whether any difference in the performance of typical children, children with global developmental delay (GDD) \& children with epilepsy was present on sensory processing sections (general processing, auditory processing, visual processing, tactile processing vestibular processing and oral sensory processing) and quadrants, Pearson chisquare was conducted.

Between typical children and children with global developmental there was significant difference observed in the auditory, tactile and oral sensory processing sections. Scored obtained by children with epilepsy were significantly different from those of typical children in all the sensory processing sections. Between children with epilepsy and children with global developmental significant difference was observed in the visual, tactile, vestibular and oral sensory processing sections as listed in Table 4.

Table 4: Chi -square result for sensory processing sections score between typical children, children with global developmental delay (GDD) and children with epilepsy and global developmental delay

\begin{tabular}{|c|c|c|c|c|c|c|c|c|c|}
\hline $\begin{array}{c}\text { Sensory processing } \\
\text { sections }\end{array}$ & \multicolumn{3}{|c|}{ Typical and GDD } & \multicolumn{3}{c|}{ Typical and Epilepsy } & \multicolumn{3}{c|}{ GDD and Epilepsy } \\
\hline & Chi-square & $d f$ & $p$-value & Chi-square & $d f$ & $p$-value & Chi-square & $d f$ & $p$-value \\
\hline Auditory & 12.16 & 2 & $.002^{*}$ & 24.34 & 2 & $<0.01^{*}$ & 2.09 & 2 & 0.35 \\
\hline Visual & 3.21 & 2 & 0.07 & 24.09 & 2 & $<0.01^{*}$ & 9.28 & 2 & $0.008^{*}$ \\
\hline Tactile & 7.64 & 2 & $0.02^{*}$ & 15.76 & 2 & $<0.01^{*}$ & 3.89 & 2 & $0.14^{*}$ \\
\hline Vestibular & 3.02 & 2 & 0.15 & 48.17 & 2 & $<0.01^{*}$ & 24.50 & 2 & $<0.01^{*}$ \\
\hline Oral-sensory & 8.37 & 2 & $0.02^{*}$ & 27.69 & 2 & $<0.01^{*}$ & 5.56 & 2 & $0.049^{*}$ \\
\hline
\end{tabular}

GDD: global developmental delay, $d f$ : degree of freedom, ${ }^{*} p$ value significant at 0.05 level

Between typical children and children with global developmental delay there was significant difference observed only in quadrant 1 . Scored obtained by children with epilepsy were significantly different from those of typical children on all the quadrants. Between children with global developmental and children with epilepsy there was significant difference on all quadrants except quadrant 1 as shown in table 5 . 


\section{International Journal of Science and Research (IJSR) \\ ISSN (Online): 2319-7064 \\ Index Copernicus Value (2013): 6.14 | Impact Factor (2014): 5.611}

Table 5: Chi -square result for quadrants score among typical children, children with global developmental delay (GDD) and children with epilepsy

\begin{tabular}{|c|c|c|c|c|c|c|c|c|c|}
\hline Quadrants & \multicolumn{3}{|c|}{ Typical and GDD } & \multicolumn{3}{c|}{ Typical and epilepsy } & \multicolumn{3}{c|}{ GDD and Epilepsy } \\
\hline & Chi-square & $d f$ & $p$-value & Chi-square & $d f$ & $p$-value & Chi-square & Df & $p$-value \\
\hline Quadrant 1 & 27.69 & 2 & $<0.01^{*}$ & 48.16 & 2 & $<0.01^{*}$ & 3.36 & 2 & 0.24 \\
\hline Quadrant 2 & 5.0 & 2 & 0.08 & 28.56 & 2 & $<0.01^{*}$ & 6.50 & 2 & $0.04^{*}$ \\
\hline Quadrant 3 & 0.8 & 2 & 0.67 & 16.25 & 2 & $<0.01^{*}$ & 9.87 & 2 & $.007^{*}$ \\
\hline Quadrant 4 & 1.02 & 2 & 0.32 & 28.20 & 2 & $<0.01^{*}$ & 20.00 & 2 & $<0.01^{*}$ \\
\hline
\end{tabular}

GDD: global developmental delay, $d f$ : degree of freedom, Quadrant 1: Low registration, Quadrant 2: sensation seeking, Quadrant 3: sensation sensitivity, Quadrant 4: Sensation Avoiding, * $p$ - value significant at 0.05 level

\subsection{Frequency of Behaviors Occurrence}

Percentage of behaviors reported as always and frequently on the sensory profile in each group is listed in table 6. Children with epilepsy demonstrated abnormal behaviors exclusively in many items (item 5, item10, item13, item16,

Table 6: Percentages of typical children, children with global developmental delay (GDD) and children with epilepsy and global developmental delay who always or frequently displayed the behaviors on the items of sensory profile

\begin{tabular}{|c|c|c|c|}
\hline Items $^{\mathrm{a}}$ & \begin{tabular}{|c|} 
Typical \\
Children \\
$(\%)$
\end{tabular} & $\begin{array}{l}\text { GDD } \\
(\%)\end{array}$ & $\begin{array}{c}\text { GDD with } \\
\text { epilepsy } \\
(\%)\end{array}$ \\
\hline General Processing & & & \\
\hline 1. My child's behavior deteriorates when the schedule change & 3.3 & 3.3 & 16.7 \\
\hline 2. My child avoids playing with others & 1.7 & 13.3 & 26.7 \\
\hline $\begin{array}{l}\text { 3. My child withdraws from situations } \\
\text { Auditory Processing }\end{array}$ & 1.7 & 3.3 & 33.3 \\
\hline 4. I have to speak loudly to get my child's attention & 1.7 & 13.3 & 33.3 \\
\hline 5. I have to touch my child to gain attention & None & 3.3 & 26.7 \\
\hline 6. My child enjoys making sounds with his/her mouth & 73.3 & 60 & 63.3 \\
\hline 7. My child takes a long time to respond, even to familiar voices & None & 10 & 26.7 \\
\hline 8. My child startles easily at sound, compared to other children the same age & 28.3 & 13.3 & 23.3 \\
\hline 9. My child is distracted and/or has difficulty eating in noisy environment & 8.3 & 3.3 & 26.7 \\
\hline 10. My child ignores me when I'm talking & None & 6.7 & 30 \\
\hline 11. My child tries to escape from noisy environments & 8.3 & None & 23.3 \\
\hline 12. My child finds ways to make noise with toys & 80 & 50 & 46.7 \\
\hline 13. It takes a long time for my child to respond to his/her name when is called & None & 13.3 & 36.7 \\
\hline $\begin{array}{l}\text { Visual processing } \\
\text { 14. My child enjoys looking at moving or spinning object }\end{array}$ & 63 & 53 & 43 \\
\hline 15. My child enjoys looking at shiny objects & 48.3 & 50 & 36.7 \\
\hline 16. My child avoids eye contact with me & None & 3.3 & 33.3 \\
\hline 17. My child refuses to look at book with me & 1.7 & 13.3 & 40 \\
\hline 18. My child does not recognize self in the mirror & 5.0 & 20 & 26.7 \\
\hline 19. My child enjoys looking at own reflection in the mirror & 90 & 63.3 & 53.3 \\
\hline $\begin{array}{l}\text { 20. My child prefers fast-paced, bright colored TV shows } \\
\text { Tactile processing }\end{array}$ & 38.3 & 53.3 & 33.3 \\
\hline 21. My child resists being held & 13.3 & 16.7 & 36.7 \\
\hline 22. My child becomes agitated when having hair washed & 23.3 & 20 & 40 \\
\hline 23. My child avoids getting face/nose wiped & $\mathbf{1 0 . 0}$ & 10 & 23.3 \\
\hline 24. My child is distressed when having nails trimmed & 10 & 16.7 & 40 \\
\hline 25. My child resists being cuddled & None & 13.3 & 40 \\
\hline 26. My child is upset by changes in the bath water temperature, from one bath to the next & 1.7 & 3.3 & 16.7 \\
\hline 27. My child avoids contact with rough or cold surfaces (for example, squirms, arches, cries) & 3.3 & 3.3 & 20 \\
\hline 28. My child becomes very upset if own clothing, hands and/or face are messy & 16.7 & 10 & 23.3 \\
\hline $\begin{array}{l}\text { 29. My child gets upset with extreme differences in room temperature (for example, hotter, } \\
\text { colder) }\end{array}$ & 6.7 & 3.3 & 16.7 \\
\hline $\begin{array}{l}\text { 30. My child becomes anxious when walking or crawling on certain surfaces (for example, grass, } \\
\text { sand, carpet, tile) }\end{array}$ & 1.7 & 6.7 & 6.7 \\
\hline 31. My child enjoys playing with food & 63.3 & 26.7 & 50 \\
\hline 32. My child seeks opportunities to feel vibrations (for example, stereo speakers, washer, dryer) & 63.3 & 60 & 53.3 \\
\hline 33. My child bumps into things, seeming to not notice objects in the way & 6.7 & 3.3 & 20 \\
\hline 34. My child enjoys splashing during bath time & 71.7 & 66.7 & 46.7 \\
\hline $\begin{array}{l}\text { 35. My child uses hands to explore food and other textures } \\
\text { Vestibular Processing }\end{array}$ & 35 & 36.7 & 60 \\
\hline $\begin{array}{l}\text { 36. My child requires more support for sitting than other children the same age (for example, infant } \\
\text { seat, pillows, towel roll) }\end{array}$ & None & 46.7 & 70 \\
\hline
\end{tabular}

item 25 and 36). Children with epilepsy displayed notable differences on item 1 , item 2 , item 3 , item 4 , item 11 , item 17 , item 18 , item 21 , item 24 , item 26 , item 27 , item 39 , item 40 and item 41 than normal and children with global developmental delay 


\section{International Journal of Science and Research (IJSR) \\ ISSN (Online): 2319-7064}

Index Copernicus Value (2013): 6.14 | Impact Factor (2014): 5.611

\begin{tabular}{|c|c|c|c|}
\hline 37. My child enjoys physical activities (for example, swinging, rocking, car ride) & 95 & 66.7 & 73.3 \\
\hline 38. My child enjoys rhythmical activities (for example, swinging, rocking, car rides) & 95 & 66.7 & 73.3 \\
\hline 39. My child becomes upset placed on back to change diapers & 6.7 & 10 & 23.3 \\
\hline 40. My child resists having head tipped back during bathing & 1.7 & 13.3 & 33.3 \\
\hline 41. My child cries or fusses whenever I try to move him/her & 1.7 & 3.3 & 30 \\
\hline $\begin{array}{l}\text { Oral Sensory Processing } \\
\text { 42. My child likes / chews on non food objects }\end{array}$ & 33 & 43 & 53 \\
\hline 43. My child mouths objects & 63.3 & 73.3 & 66.7 \\
\hline 44. My child is unaware of food or liquid left on lips & 6.7 & 6.7 & 50 \\
\hline 45. My child refuses all but a few food choices & 5 & 10 & 16.7 \\
\hline 46. My child resists having teeth brushed & 6.7 & 13.3 & 20 \\
\hline 47. My child refuses to drink from a cup & 1.7 & 3.3 & 10 \\
\hline 48. My child refuses to try new foods & 3.3 & 3.3 & 6.7 \\
\hline
\end{tabular}

GDD: global developmental delay; ${ }^{a}$ Bold item are those in which three group did not show much diffrence

\section{Discussion}

In this study 60 typical children, 30 children with global developmental delay, and 30 children with epilepsy and global developmental delay participated and their score on infant toddler sensory profile was obtained. This study assessed the difference in the performance of typical children, children with global developmental delay (GDD) $\&$ children with epilepsy on sensory processing sections(general processing, auditory processing, visual processing, tactile processing, vestibular processing, and oral sensory processing) of sensory profile.

Result from this study demonstrated significant difference in the performance of typical children, children with global development delay and children with epilepsy on infant toddler sensory profile. It also supported the hypothesis that sensory profile is useful in discriminating behavior of typical children with children with epilepsy and children with global developmental delay.

In this study, children with typical development differed significantly from children with global developmental delay and epilepsy in all sensory processing sections. High proportion of children with epilepsy (more than 25\%) demonstrated definite difference in auditory processing section than the other two groups. Children with global developmental delay also exhibited definite difference in the same but in less proportion when compared to children with epilepsy. More than $20 \%$ children with epilepsy showed definite difference in visual processing section where as the other groups exhibited typical performance. In tactile processing section $10 \%$ of children with epilepsy demonstrated definite difference. When comparing the performance of the three groups on vestibular processing section, more than $30 \%$ of children with epilepsy showed definite difference whereas, in oral processing section $6 \%$ children showed definite difference when compared with the other groups. Only 3\% children with GDD showed definite difference in vestibular and oral processing section, which was half of the group in epilepsy. Results show significant differences between the three groups on all the sensory processing sections of the sensory profile. However, higher percentage of children with epilepsy showed definite difference than children with global developmental delay.

On further analysis of the data based on the four quadrants of the sensory profile namely: slow registration, sensation seeking, sensory sensitivity and sensation avoiding, high percentage of children with epilepsy showed definite difference in all the four quadrants. $30 \%$ children with global developmental delay and $50 \%$ children with epilepsy demonstrated definite difference on quadrant one of sensory profile indicating low registration as compared to the typical children. On quadrant two, all the groups demonstrated definite difference but the percentage was higher in children with epilepsy indicating sensory seeking behavior.

Sensory processing patterns of typical children differed distinctly with those of children with epilepsy. On more than $50 \%$ of the item (Table no. 6) of the sensory profile children with epilepsy had more representation than children with typical development and children with global developmental delay. It is interesting to note that items exhibited by children with epilepsy were uncommon for typical children.

It may be noted that the sensory profile obtains the sensory responsivity patterns in six sections namely, general processing, auditory processing, visual processing, tactile processing, vestibular processing and oral sensory processing. However, the norms are not provided for the general processing category.

When analyzing the performance of items in each sections, seven items (item no $4,5,7,9,10,11,13$ ) in auditory section, children with epilepsy were found to demonstrate the behavior always or frequently more than normal children. In visual processing section, three items (item no $16,17,18$ ) were demonstrated always or frequently by children with epilepsy more when compared with other two groups. When comparing the occurrence of behavior in tactile section children with epilepsy demonstrated six items (item no $21,22,24,25,27,35$ ) more frequently or almost always then typical children and children with global developmental delay. Four out of six items (item no. 36, 39, $40,41)$ in vestibular processing section children with epilepsy were found to demonstrate the behavior always or frequently more than other two groups. In oral processing section only two items (item no 44 and 45 was demonstrated always or frequently by children with epilepsy more than other groups.

Thus comparing the performance of items in each category, three of the five categories (i.e., auditory processing, tactile processing and vestibular processing) had highest no of items, in which children with epilepsy demonstrated frequently. This observation is important because these 


\section{International Journal of Science and Research (IJSR) \\ ISSN (Online): 2319-7064}

Index Copernicus Value (2013): 6.14 | Impact Factor (2014): 5.611

categories represent the most commonly examined sensory systems in the literature of sensory integration.

Eight items for e.g. Auditory item no.6 and item no.12, visual item no. 14, and item no. 19, tactile item no. 31 and vestibular item no. 32 , item no. 37 and item no. 38 were very common for typical children demonstrating sensory seeking behavior. This finding is similar to the results of Erner and Dunn (1997) who established a high incidence of behavior in sensation seeking quadrant for typical children. Overall, in 12 of the items (shown as bold in table: 6) the three group did not show much difference. This might indicate that these common behaviors are not very reliable for discriminating purpose between typical children, children with global developmental delay and children with epilepsy. Thus caution must be observed in drawing inferences on these items.

\section{Limitations}

A convenience cross sectional sample was used in this study and therefore may not represent the entire population of children with epilepsy.

\section{Recommendations}

Since sensory problems are found to be common in children with epilepsy further research is needed to clearly define the patterns of sensory responsivity in children with epilepsy and to investigate the relationship of these patterns to the occupational performance of children with epilepsy.

\section{Conclusion}

The sensory issues seem to be more common in children with epilepsy and their responses vary from hyposensitivity to hypersensitivity. The study outcome emphasizes the need for assessment of sensory systems followed by early intervention with mothers' active participation. Sensory issues experienced by children with epilepsy are much more common than found to be. Defects in sensory processing and integration might be responsible for behavioral problems that occur in children with epilepsy. It also gives expression to give caution to some items, as they are common in the three groups. The reason of this disorder could be related to neurological immaturity as seen in children with epilepsy.

\section{References}

[1] Austin, J.K. (1992). Correlates of behavior problems in children with epilepsy. Epilepsia, 33(6),111522.Buelow, J.M., Austin, J.K., Shen, J., Dunn, D.W., \& Fastenau, P.S. (2003). Behavior and Mental health problems in children with epilepsy and low IQ. Dev Med Child Neurol 2003,45(10), 683-92

[2] Barnek, G.T. (1999). Autism during infancy: A retrospective video analysis of sensory -motor and social behaviors at 9-12 months of age. Journal of Autism and developmental Disorders, 29, 213-224

[3] Clarke, D.F., Roberts W, Darakshan, M. (2005). The prevalence of autistic spectrum disorder in children surveyed in a tertiary care epilepsy clinic. Epilepsia, 46, 1970-1977

[4] Dunn, W. (1994). Performance of typical children on the sensory profile: An item analysis. The American Journal of Occupational Therapy, 48(11), 967-994.

[5] Dunn, W. (1996). The impact of sensory processing abilities on the daily lives of young children and their families: A conceptual model. Infants and young children 9(4), 23-35.

[6] Dunn, W., \& Westman, K. (1997). The Sensory Profile: The performance of a national sample of children without disabilities. American Journal of Occupational Therapy, 51, 25-34.

[7] Dunn, W., \& Brown, C. (1997). Factor analysis on the sensory profile from a national sample of children without disabilities. The American Journal of Occupational Therapy, 51, 490-495.

[8] Dunn, W., \& Daniels, D. (2001). Initial development of the infant toddler sensory profile. Journal of Early Intervention, 25(1), 27-41.

[9] Dunn, W. (2001). The sensations of everyday life: Theoretical, conceptual and pragmatic considerations. American Journal of Occupational Therapy, 55(6), 608- 620 .

[10]Dunn, W. (2002). The Infant/Toddler Sensory Profile manual. San Antonio, TX: The Psychological Corporation.

[11]Dunn, W., \& Bennett, D. (2002). Patterns of sensory processing in children with attention deficit hyperactivity disorder. Occupational Therapy Journal of Research 22(1), 4-15.

[12] Ermer, J., \& Dunn, W. (1998). The Sensory Profile: A discriminant analysis of children with and without disabilities. American Journal of Occupational Therapy, 52(4), 283-290.

[13] Johnson-Ecker, C. L., \& Parham, L. D. (2000). The evaluation of sensory processing: validity study using contrasting groups. American Journal of Occupational Therapy, 54, 494-503.

[14] Kientz, M. A., \& Dunn, W. (1997). Comparison of the performance of children with and without autism on the sensory profile. American Journal of Occupational Therapy, 51, 530-537.

[15] Myles, B. S., Hagiwara, T., Dunn, W., Rinner, L., Reese, M., Huggins, A., et al. (2004). Sensory issues in children with Asperger syndrome and autism. Education and Training in Developmental Disabilities, 3(4), 283290

[16] Oostrom, KJ., Smeets-Schouten, A., Kruitwagen, CL., Peters, AC.,\& Jennekens-Schinkel, A.(2003). For the Dutch Study Group of Epilepsy in Childhood. Not only a matter of epilepsy: early problems of cognition and behavior in children with "epilepsy only" - a prospective, longitudinal, controlled study starting at diagnosis. Pediatrics 112, 1338-44.

[17] Padankatti, M. (2005). A comparison of the performance of children with and without learning disability on the sensory profile tool. The Indian Journal of Occupational Therapy, 26(3), 63-69.

[18]Prakash, A.J.,\&Vaishampayan, A. (2007). A preliminary study of the sensory processing abilities of children with cerebral palsy and typical children on the 


\section{International Journal of Science and Research (IJSR) \\ ISSN (Online): 2319-7064}

Index Copernicus Value (2013): 6.14 | Impact Factor (2014): 5.611

sensory profile. The Indian journal of Occupational Therapy 39(2), 27-34

[19] Rogers, S., Hepburn, S., \& Wehner, E. (2003). Parent report of sensory symptoms in toddlers with autism and those with other developmental disorders. Journal of Autism and Developmental Disorders, 33(6), 631- 642.

[20] Singhi, P., Jagirdar, S., \& Malhi, P. (2003). Epilepsy in children with cerebral Palsy. J Child Neurol, 18, 174179

[21] Watling, R., Dietz, J., \& White, O. (2001). Comparison of sensory profile scores of young children with and without autism spectrum disorders. American Journal of Occupational Therapy, 55(4), 416-423. 